\title{
Review on Breeding Potato (Solanum tuberosum L.) Genotypes for Processing Quality Traits
}

\author{
Ebrahim Seid ${ }^{*} \quad$ Lemma Tessema \\ Ethiopia Institute of Agricultural Research (EIAR), Holetta Agricultural Research Centre (HARC), \\ P. O. Box: 2003, Addis Ababa, Ethiopia
}

\begin{abstract}
Potato (Solanum tuberosum L.) is a rich source of protein, energy, vitamins and minerals. Potato is in the family Solanaceae with chromosome numbers vary from diploid $(2 n=2 x=24)$ to hexaploid $(2 n=6 x=72)$. In Ethiopia, the major objectives of potato breeding was targeted at selection of clones for high yield, wide adaptability and resistance for late blight, hence processing qualitative traits were not the main targets in potato breeding program still near future. Therefore, the objective of this review article is to discuss breeding potato genotypes for desirable processing quality traits. Tuber shape is a syndrome of many characters that considers the length/width ratio for describing the overall shape; it varies from compressed/round to long. The yellow pigment in potato tuber flesh is caused by various carotenoids that may protect against cancer, cardiovascular disease, and macular eye degeneration. The genetics of morphological traits are Tuber flesh color, skin color and tuber shape and eye depth. To minimize waste, varieties with long tubers are preferred for French fries and varieties with round tubers are ideal for crisps. Eye depth is an important trait of tuber quality because deep eyes affect the appearance of tubers and add to the cost of peeling in processing factories. Tuber quality traits in potato are specific gravity, dry mater content, starch content, Glycolalkaloids and tuber size uniformity. Specific gravity of potatoes is commonly used by the potato processing industry as a tool for quick estimation of dry matter content, as both are highly correlated. Tuber dry matter content and specific gravity significantly influenced by the interaction effect of growing environment and cultivars. Processing quality usually has relatively low to moderately high heritability, depending on the progenitor materials. Therefore, multiple location tests over several years are often required in order to determine whether a clone has indeed a high processing quality.
\end{abstract}

Keywords: Potato breeding; Tuber quality; Dry mater content; Specific gravity; Processing.

DOI: $10.7176 / \mathrm{JNSR} / 12-13-03$

Publication date:July $31^{\text {st }} 2021$

\section{Introduction}

Potato (Solanum tuberosum L.) is one of the most important tuber crops, is used worldwide for human and animal consumption, and as raw material for starch and alcohol production (Storey, 2007). Potato is the third most important food crop in the world after rice and wheat in terms of human consumption. More than a billion people eat potato worldwide, and global total production exceeds 300 million metric tons (CIP, 2021). It is a nutritious vegetable containing $16 \%$ carbohydrates, $2 \%$ proteins, $1 \%$ minerals, $0.6 \%$ dietary fiber and a negligible amount of fat (Gumul et al., 2011). At the highlands of Ethiopia, the potato holds great promise for improving the livelihoods of millions of smallholder farmers. The potential for high yield, early maturity and excellent food value give the potato great potential for improving food security, increasing household income and reducing poverty (Devaux et al., 2014). Potatoes are either consumed directly or they are processed to give products such as chips and French fries, mashed and canned potatoes. Besides being important in human diet, potatoes are also used as animal feed and as raw material for starch production. In general, different cultivars have different uses. Red-skinned cultivars with low dry matter content are used for fresh market, whereas long types are suitable for French fries. The amount of potatoes that are used for processing is increasing. In USA and in several European countries, more than $50 \%$ of tuber yield is given to the processing industry (Carputo et al., 2004).

One of the most important aspects related to this versatile crop is its quality. Quality parameters change according to the specific market utilization types, and are often referred to two major categories. The first category groups "external quality", aspects comprising skin colour, tuber size and shape, eye depth. These traits are deemed very important for fresh consumption where external traits are most likely to influence consumer's choice. The second category comprises "internal quality" aspects including nutritional properties, culinary value, after cooking properties or processing quality. Internal quality is given by traits such as dry matter content, flavor, sugar and protein content, starch quality, type and amount of glycoalkaloids. The potato needs a continued improvement of quality traits to meet the needs of a changing and demanding world (Carputo et al., 2004).

There are several factors affecting tuber quality, such as the genetic makeup of the cultivar, crop maturity, agronomic practices, environmental conditions, storage temperatures, the presence of pests and diseases. The genetic makeup is the most important factor that influences quality attributes (Carputo et al., 2004). Traits that are genetically controlled can be grouped as follows: one biological traits (proteins, carbohydrates, vitamins, 
minerals, reduced amounts of toxic glycoalkaloids; two sensorial traits (flavour, texture, colour); and three industrial traits (tuber shape and size, dry matter content, cold sweetening, oil absorption, starch quality). Breeding for resistance to late blight and high yield have been the main priorities of Ethiopia's potato breeding program in the past years. A lot of efforts have been made and several improved varieties have been released with these characteristics. In addition, the country has a potential in producing potatoes to supply large scale potato processing industries that might not be far from establishment (Wassu, 2016). In Ethiopia, the major objectives of potato breeding was targeted at selection of clones for high yield, wide adaptability and resistance for late blight, hence processing qualitative traits were not the main targets in potato breeding program still near future. However, the need of processing qualitative traits for potato breeders is demanding due to the ever increasing claim of post-harvest quality in potato for emerging industries in the country. Therefore, the objective of this review article is to discuss breeding potato genotypes for desirable processing quality traits.

\section{Breeding Achievement in Ethiopia}

Strategic potato research in Ethiopia began in 1975 with the understanding of the constraints challenging its production and productivity (Baye and Gebremedhin, 2013). In Ethiopia, more than 39 potato improved varieties (Belete, Gudanie, Dagim and Jalene...) have been released by different research centers and institutions. However, the released varieties have not satisfied the consumer for processing quality purpose. Among 39 potato varieties 37 varieties has been characterized by focusing on developing high yielding, wide adaptability and late blight resistant varieties and also the rest two varieties were developed for processing quality and $\mathrm{Fe}$ and $\mathrm{Zn}$ purpose, respectively (Figure 1).

Nevertheless, through consistent on-farm technology demonstration integrated with training of farmers and seed growers, several varieties have been disseminated to different potato growing zones of the country. From the use of these improved technologies, farmers have been able to get considerable economic benefit and impacts in their lives and livelihoods. The most important benefit from these technologies, as indicated by the farmers themselves, has been the possibility of growing the potato crop during the main rainy season, which was a key challenge to production due to late blight (Gebremedhin et al., 2008).

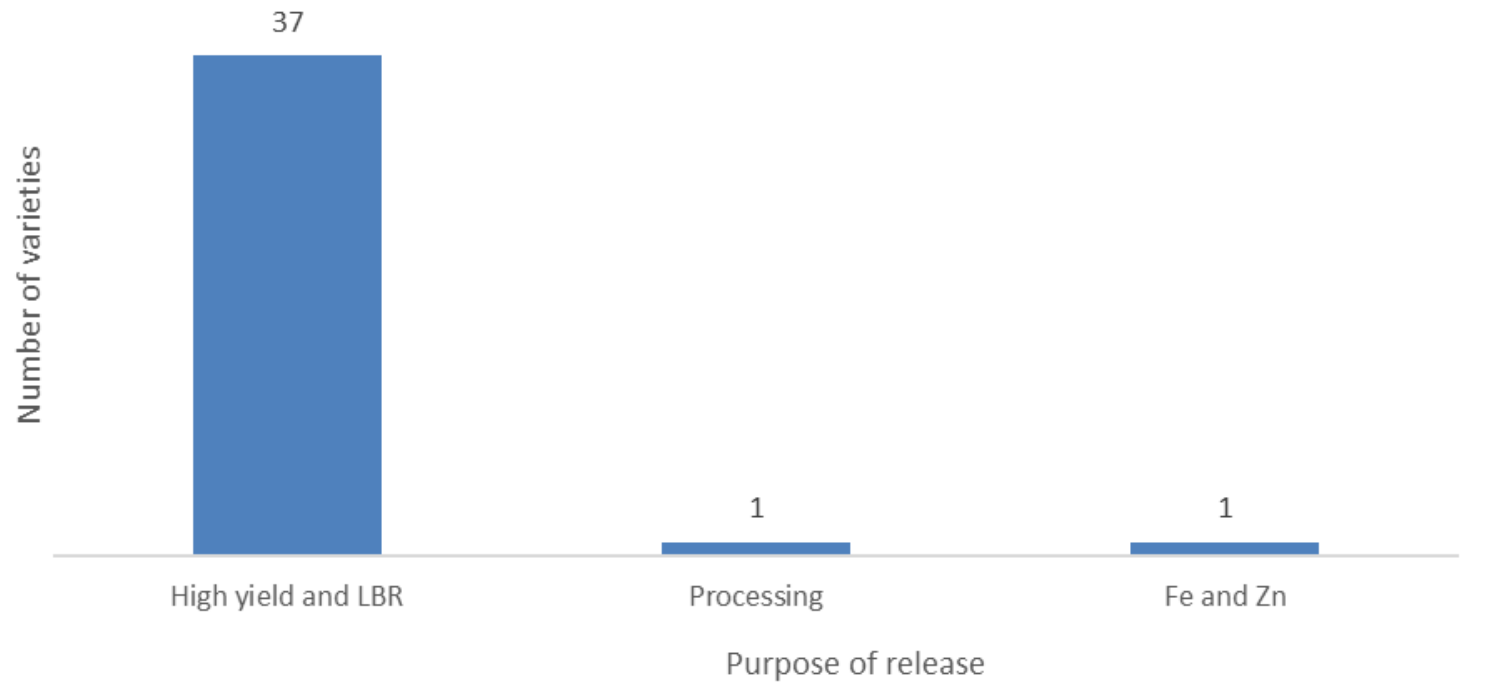

Figure 1. Varieties released achievement in Ethiopia in the past three decade

\section{Breeding for quality traits}

Most efforts of plant breeding in potato have been focused on increased yield and resistance to late blight (Bradshaw, 2007); breeding for quality has been a second priority (Werij, 2011). Conventional potato breeding refers to the development of new varieties from sexual crosses between pairs of parents with complementary features followed by clonal propagation and selection based on several traits (Brown, 2011). A potato breeder's most important decision is which parents to use in crosses. Based on experience, breeders choose parents and parental combinations that result in a relatively high proportion of desirable offspring (Jansky, 2009). Before making the crossing, it is necessary to measure the genetic variation available for a trait of interest, within cultivated species. For potatoes a large variation for quality traits has been reported (Monteros, 2011). This genetic variability can be exploited by breeders to improve the quality of the crop for the fresh and processing 
market. In potato, genetic studies have predominantly been performed using diploid populations (Werij et al., 2007; Śliwka et al., 2012). Tetraploid potatoes have been used less frequently (Meyer et al., 1998).

\subsection{Genetic Variation in Potato}

The germplasm base of potato is comprised of primitive indigenous landraces and wild Solanum species (Ovchinnikova et al., 2011). Advances in molecular techniques have provided greater insight into the taxonomic relationships of potato and there are estimated to be 100 wild species and four cultivated species (Spooner et al., 2007). Potato is a highly heterozygous out crossing species which is asexually propagated, via tubers, for food production and germplasm maintenance. Sexual propagation and the production of 'true' potato seed (TPS) allow breeders to generate genetic variation, and as a clonal crop, there are opportunities to exploit both additive and non-additive variation (Mackay, 2007).

Potato genetic variation vary in ploidy levels (diploid to pentaploid) and show a high degree of diversity in tuber size, shape, skin and flesh colour, storage ability and cooking quality (Andre et al., 2007). As well as indigenous and primitive landraces, there are a number of wild species of the Solanum genus of various ploidy levels that can be used as new sources of genetic diversity, for a range of economically important traits, to develop new Solanum tuberosum potato varieties (Bradshaw and Ramsay, 2005).

\subsection{The Genetics of Morphological Traits}

\subsubsection{Tuber flesh colour}

Tuber flesh color varies from white to purple; it is due to the accumulation of two different classes of pigment anthocyanins and carotenoids (Lewis et al., 1998). Anthocyanin accumulation leads to red, blue or purple flesh colors (Hung et al., 1997). Red and purple-fleshed potatoes have acylated glucosides of pelargonidin while purple potatoes have, in addition, acylated glucosides of malvidin, petunidin, peonidin, and delphinidin (Brown, 2005; Lachman et al., 2009). Colored potatoes may serve as a potential source of natural anthocyanin pigments, since they are low-cost crops (Jansen and Flamme, 2006), and also are a significant source of potato antioxidant micronutrients (Andre et al., 2007; Nayak et al., 2011). Thus, purple and red-fleshed potatoes could be used as novel sources of natural colorants and antioxidants with added value for the food industry and human health (Reyes et al., 2004). Antioxidant values for red-fleshed types ranged as high as $300 \%$ of the white flesh, while for purple fleshed antioxidant values reached $250 \%$ of the white flesh (Brown, 2005). Several studies have indicated that anthocyanins have high free-radical scavenging activity, which helps to reduce the risk of chronic diseases and age-related neuronal degeneration (Teow et al., 2007). Carotenoid levels determine whether the tuber flesh is white, yellow or orange it is controlled by the single dominant allele at the Y locus on potato chromosome III (Bonierbale et al., 1988)

\subsubsection{Tuber skin color}

One of the most easily noticeable traits of potato tubers is the skin color. This character ranges from white-cream to blackish. The tuber skin color is controlled by different genetic systems that control the presence and absence of red and blue pigments. The potato $\mathrm{R}$ locus is required for the production of red anthocyanins, which have been shown to be derivatives of pelargonidin, while $\mathrm{P}$ is required for the synthesis of purple pigments, which are typically derived from petunidin (Dodds and Long, 1955; Lewis et al., 1998). A third locus, I, is required for the synthesis of red or purple anthocyanins in tuber skin (Dodds and Long, 1955). All three of these loci have been mapped in the potato genome (van Eck et al., 1994).

\subsubsection{Tuber shape and eye depth}

Tuber shape is a syndrome of many characters, that considers the length/width ratio for describing the overall shape, it varies from compressed/round to long (Van Eck, 2007; Werij, 2011). The shape of the tuber is one of the most eye-catching traits of the potato crop (Van Eck et al., 1994). The tuber shape which is most favoured depends on the actor in the potato food chain. To minimize waste, varieties with long tubers are preferred for French fries and varieties with round tubers are ideal for crisps (Van Eck et al., 1994, Kirkman, 2007). Eye depth is also an important component of tuber quality as it adds to the cost of peeling and affects the general appearance (Li et al., 2005).

Tuber shape and eye depth showed a large variation, from compressed to elongate and from shallow to very deep, respectively. These distributions suggest a polygenic inheritance. However, at the diploid level some studies have concluded that the inheritance is monogenic and regulated by the Ro locus for tuber shape (Van Eck et al., 1994) and Eyd locus for eye depth (Li et al., 2005). To analyze if tuber shape follows a Mendelian model of segregation, the eight classes identified were reduced to three (round, oval and long) as was done in other populations studied (De Jong and Burns, 1993; Li et al., 2005).

\subsection{Tuber Quality Traits in Potato}

Quality is one of the most important characteristics of potato and its quality is dependent on external and internal aspects of the tuber. However, various workers have pointed out that the true quality of potato is directly linked 
with its dry matter content (Dale and Mackay, 1994); an important attribute to both the food and nonfood potato industries determining both the quality and yield of the processed product (Haase, 2004). Consequently, potato varieties with a dry matter content of $20 \%$ or higher, a starch content of $13 \%$ and above and/ or a specific gravity of 1.08 or higher are the most preferred for processed products (Kirkman, 2007).

\subsubsection{Specific gravity}

Tuber specific gravity, which is a measure of dry matter content, is a critical processing quality trait. Cultivars with high dry matter are required for the production of fries, chips, and starch. The genotype-environment interaction for specific gravity is generally low, so rankings of cultivars do not change across years and production environments (Killick and Simmonds, 1974). On the contrary, Elfnesh et al. (2011) and Tesfaye et al. (2013) reported that dry matter content and specific gravity of tubers significantly influenced by the interaction effect of growing environment and cultivars. High specific gravity is often noted in tetraploid clones derived from sexual polyploidization in which the diploid parent contains wild or cultivated potato relatives (Buso et al., 2000).

\subsubsection{Dry matter content}

For the processing industry dry matter content (DMC) is also a critical component. It is a measure of the tuber internal quality, starch is the principal compound, which is a polygenic trait and the effects are located on all chromosomes (Werij et al., 2012). Kirkman (2007) established that a DMC below 19.5\% for French fries and $20 \%$ for chips potatoes is not acceptable. Similarly, a DMC of more than $25 \%$ for French fries manufacturing are not adequate. The DMC and distribution has implications for bruise susceptibility during harvest and effects on cooking type, e.g. a waxy or mealy texture when boiled, organoleptic characteristics and in processed potatoes the final product texture (Taylor et al., 2007). Dry matter content is affected by environmental factors during growth of the crop, such as solar radiation, soil temperatures, soil moisture, fertilizers and haulm killing (Haverkort, 2007). In general, cold climate and short growing seasons reduce DMC, whereas the contrary occurs in warm, sunny locations with long growing seasons and an adequate water supply.

\subsubsection{Starch content}

Starch is the major component of potato tubers, accounting for $75-80 \%$ of the tuber dry weight (Burton 1989). Its grains are small and of uniform size in young tubers. Towards tuber maturity the filling of starch into granules results in increased size and larger size distribution of granules (Burton 1989; Viola, 2000). In growing potato tubers, starch concentration increases towards maturity, and thus, mature tubers have high starch and protein concentrations, but are low in sugar (Burton, 1989). Therefore, the length of growing period of tubers has an important effect on the starch concentration of harvested tubers (Turakainen, 2007). The concentration depends on cultivar, growth conditions and cultivation practices (Burton, 1989).

\subsubsection{Glycoalkaloids}

Another important attribute that affect the taste of the tubers is glycoalkaloid content. Glycolalkaloids are naturally occurring components in all parts of the potato plant; they are secondary plant metabolites that at appropriate levels may be toxic to bacteria, fungi, viruses, insects, animals, and humans (Friedman, 1997). The glycoalkaloid content can increase during storage and transportation and under the influence of light, heat, cutting, slicing, sprouting, and exposure to phytopathogens. Their presence at low concentrations may contribute to the flavor characteristics of processed potato, but at levels above $15 \mathrm{mg}$ per $100 \mathrm{~g}$ fresh weight a bitter taste may be detected (Sinden and Webb, 1972). The consumption of large amounts of glycoalkaloids by humans could produce toxication symptoms ranging in severity from nausea to, in extreme cases, death (Friedman and Levin, 2009; Friedman et al., 1997). The majorities of glycoalkaloids in the potato tuber are located within the first $1 \mathrm{~mm}$ from the outside surface and decrease toward the center of the tuber (Friedman, 2006).

\subsubsection{Tuber size uniformity}

Uniformity of tuber size is of great economic importance, because it directly affects the marketable yield, as well as costs involved in size grading. Most studies focus on the processes of stolon initiation, elongation, swelling, tuber growth and resorption within a given genotype, across a wide range of environmental factors (Ewing and Struik, 1992). Genetic variation in size distribution across a wide range of diploid genotypes was studied by Celis Gamboa et al. (2003). Their results suggest that the final marketable yield and size distribution of potato tubers are defined by the degree of stolon branching, the duration of the stolon tip swelling period, the ability of the small growing tubers to reach a marketable size and tuber resorption. Therefore, understanding of the inheritance of tuber size uniformity might not be feasible without first understanding the inheritance of all underlying factors, which are known to be highly genotype-dependent.

\subsubsection{Greening and tuber dormancy}

Other obvious quality traits are greening and tuber dormancy. Greening is a process that involves the transformation of amyloplasts in the outer layers of the tuber to chloroplasts (Lebecka and Zimnoch-Guzowska, 2004). Greened tubers are associated with an accumulation of glycoalkaloids, which are poisonous for humans and animals. However, there is no direct metabolic link between chlorophyll biosynthesis and total glycoalkaloids content (Percival, 1999). Many factors can influence tuber greening, such as light (Griffiths and 
Dale, 2001), maturity of tubers (Buck and Akeley, 1967), time and temperature of storage (Griffiths et al., 1998), production treatments (Lewis and Rowberry, 1973) or tuber size (Parfitt and Peloquin, 1981). Although tuber greening is affected by environmental factors, variability among varieties has been reported by (Reeves, 1988). Tuber dormancy (resting period) of potato tubers is the physiological state after harvest, during which tubers do not sprout (Wiltshire and Cobb, 1996) even when stored under conditions favorable for sprouting. Two molecular mapping studies detected a number of QTLs for tuber dormancy and demonstrated the complex character of this trait (van den Berg et al., 1996). According to Werij (2011) in potato the genes involved in breaking dormancy and the following sprouting action, can be divided in several categories. A first group concerns the genes coding for homeotic proteins and transcription factors (Faivre-Rampant et al., 2004). A second class of genes regulates hormone metabolism and hormone response. Abscisic acid and ethylene are mentioned as requirement for dormancy induction, while abscisic acid maintains dormancy and cytokinins are involved in loss of dormancy (Suttle, 2004). The third group of genes is involved in metabolism of reserve storage molecules (Agrimonti et al., 2007).

\section{Tuber Quality Traits for Table Purpose}

Quality characteristics are broadly defined as those traits that determine the degree to which tubers are fit-forpurpose for their intended end-use (Simmonds, 1979). Consumers requirements for the fresh market are often associated with the morphological features (shape, depth of eyes, skin and flesh color), together with greening, dormancy and taste. Furthermore these traits are also important for farmers and traders as we demonstrate. These characters determine the acceptability of the tuber. However, for farmer's agronomic traits as late blight resistance and yield are important to consider in the definition of the ideotype of potato for the fresh market. High tuber yield is one of the most important selection criteria of the breeding scheme for the development of new potato varieties and is also an important selection criterion for farmers in Ethiopia.

In the case of potato several traits influence the preference of the farmers, traders and consumers. These characters are mainly agronomic, tuber quality and tuber processing related characteristics. Consumers' requirements regarding tuber quality for fresh market potatoes are often associated with the visual characteristics of the product; in the case of potato the shape, tuber size, skin and flesh color and appearance of the tuber were the preferred characteristics by consumers (Storey, 2007). An important character that affects the taste and safe consumption of potato for the fresh market is total glycoalkaloid content in tubers, which is an important criterion of selection in the potato-breeding scheme, since glycoalkaloids can be passed to progenies during breeding (Kozukue et al., 2008).

Most of the consumers prefer a variety suitable for several types of food preparation (mashed potato, soups, fries, salad or cooked). However, to get a variety with all these characteristics is a difficult task because each food preparation has specific requirements regarding tuber quality. For example for fried potatoes a variety with high dry matter content (DMC) and low reducing sugar content is necessary (Storey, 2007), while, potatoes for soups or stews should maintain their consistence after cooking then a low dry matter content potato is required (Taylor et al., 2007). Culinary uses of potato varieties are related to their texture (Jansky, 2010).

Flavor is due to the combination of taste, aroma, and texture. Raw potatoes are bland, but become more flavorful when heated, as a result of chemical changes (Maga, 1994). Although potatoes are not considered to have a strong flavor, the components of flavor are complex (Coleman et al., 1981). Pyrazines are considered to be among the most important and characteristic components of baked potato flavor (Buttery et al., 1973). They are produced by the non-enzymatic maillard reaction, in which sugars interact with amino acids at high temperatures. There is a strong positive relationship between pyrazines and organoleptic quality in both baked potatoes (Maga and Holm, 1992) and potato chips (Maga and Sizer, 1973).

\section{Quality traits for the processing market}

For the processing market, tuber shape, eye depth, dry matter content, Enzymatic discoloration (ED) and reduce sugar content (RSC), are crucial traits that affect the product-manufacturing efficiency (Storey, 2007). Round tuber shape is preferred for crisps and long shape is ideal for French fries potatoes. Furthermore, shallow eyes are preferred in both cases (Van Eck, 2007).

Dry matter content (DMC) and the level of sugar content in potato tubers are important factors that affect quality in potatoes (Storey, 2007). Despite dry matter content is strongly influenced by the environment (Laboski and Kelling, 2007), it is genetically controlled and selection of suitable varieties offers the best means of producing high DMC potatoes (Hughes, 1974). The concentration of reduce sugar content (RSC) is genetically determined (Menendez et al., 2002), and selection for low RSC germplasm is possible through breeding evaluation. Tuber maturity, fertilization, temperature and soil moisture are some of the factors that affect the resulting sugar accumulation in newly harvested tubers (Sowokinos, 2007). Enzymatic discoloration, which is a significant problem in the food industry, is one of the main causes of quality loss during postharvest handling (Coetzer et al., 2001). This discoloration results in considerable economic losses for the food processing and 
retail industry (Werij et al., 2007).

\section{Selection Methods for Tuber Quality Traits}

Once genetic variability has been produced, it is necessary to identify selection procedures that reduce time and costs. This is particularly important when breeding programs based on inter specific hybridization are pursued. Indeed, one main constrain in the use of wild species is that, together with useful traits, they can transfer characteristics that are undesired from the commercial standpoint. In the case of Solanum species, traits such as long stolons, deep eyes, and negative quality traits can be transmitted. As reported by Pavek and Corsini (2001), transmission of undesired traits has very much limited the use of potato genetic resources. Therefore, after inter specific crosses, time-consuming evaluation and selection are necessary to eliminate unwanted wild-type genes and restore the cultivated improved phenotypes.

Progress in molecular genetics and associated technologies have paved the way for the development of new and powerful tools in aid of potato breeders. Marker-assisted selection is perhaps the most powerful approach that uses DNA markers efficiently. Tagging chromosome segments bearing desired alleles with these markers could be particularly useful in the selection of inter specific hybridization because it efficiently reduces the linkage drug in terms of time and space. The use of DNA markers can be ascribed not only to the use of markers tightly linked to target genes (positive assisted selection), but also in the use of markers specific for the wild donor parent to perform selection against the wild genome negative assisted selection (Barone, 2004).

Negative assisted selection approach to transfer useful traits from Solanum Commersonii to Solanum tuberosum gene pool within our breeding program. S. commersonii is a diploid wild species with several useful traits, such as frost resistance, acclimation capacity, high dry matter content of tubers, resistance to Ralstonia solanacearum. However, due to the presence of demissine, tomatine and commersonine, glycoalkaloid content in the tubers of this species is too high. It is well known that potato glycoalkaloids are extremely toxic to humans and animals, and that the glycoalkaloid content of newly developed genotypes should be carefully determined (Korpan et al., 2004).

\section{Challenges for Improving Processing Quality Traits}

Processing quality usually has relatively low to moderately high heritability, depending on the progenitor materials (Tarn et al. 2006). Despite clear differences among cultivars indicating genetic variation, environmental conditions can often give rise to phenotypic variation within cultivars that are almost as great as inter cultivar differences. Therefore, multiple location tests over several years are often required in order to determine whether a clone has indeed a high processing quality (Dale and Mackay, 1994; Love et al. 1998). This seasonal or environmentally induced variation creates difficulties for conventional selection and breeding of processing quality traits. Consequently, high expectations have been placed in biotechnological solutions for rapid and effective improvements to the processing quality of potato.

\section{Summary and Conclusion}

Breeding potato for quality traits requires a continuous flow of new genes and allelic diversity into the $S$. tuberosum gene pool. The quality in potato is defined as the sum of favorable characteristics of the tuber. A complex set of external and internal quality traits are required for fresh and processing potatoes. External quality traits include tuber shape, eye depth, skin and flesh color but also dormancy and greening are important. Internal quality traits include the content of dry matter (DMC), reducing sugars (RSC), glycoalkaloids, enzymatic discoloration (ED) and nutritional quality. The true quality of potato is directly linked with its dry matter content. For making chips of uniform size, the tubers should be round to oval in shape having a diameter of $45-80 \mathrm{~mm}$. For French fries, oblong to long tubers having $>75 \mathrm{~mm}$ length are preferred. potato varieties with a dry matter content of $20 \%$ or higher, a starch content of $13 \%$ and above and/ or a specific gravity of 1.08 or higher are the most preferred for processed products Consumers requirements for the fresh market are often associated with the morphological features (shape, depth of eyes, skin and flesh color), together with greening, dormancy and taste. Furthermore these traits are also important for farmers and traders as we demonstrate.

There are several factors affecting tuber quality. They include the genetic makeup of the cultivar, crop maturity, agronomic practices, environmental conditions, storage temperatures, the presence of pests and diseases. The genetic makeup is the most important factor that influences quality attributes. Tuber dry matter content and specific gravity significantly influenced by the interaction effect of growing environment and cultivars. It is a measure of the tuber internal quality, starch is the principal compound, which is a polygenic trait and the effects are located on all chromosomes.

\section{Conflict of interest}

The authors declare no conflict of interest. 


\section{References}

Agrimonti, C., Visioli, G., Bianchi, R., Torelli, A., Marmiroli, N., 2007. G1-1 and LeG1-1/LeG1- genes are involved in meristem activation during breakage of dormancy and early germination in potato tubers and tomato seeds. Plant Science, 173: 533-541.

Andre, C.M., Ghislain, M., Bertin, P., Oufir, M., del Rosario Herrera, M., Hoffmann, L., Hausman, J.F., Larondelle, Y. and Evers, D., 2007. Andean potato cultivars (Solanum tuberosum L.) as a source of antioxidant and mineral micronutrients. Journal of agricultural and food chemistry, 55(2): 366-378.

Barone, A., 2004. Molecular marker-assisted selection for potato breeding. American Journal of Potato Research, 81(2): 111-117.

Baye, B., Gebremedhin, W., 2013. Potato research and development in Ethiopia: achievements and trends. In: G Woldegiorgis, S Schulz, B Berihun (edr)Seed Potato Tuber Production and Dissemination Experiences, Challenges and Prospects. EIAR and ARARI, Bahir Dar, Ethiopia, Pp. 35-44.

Bonierbale, M.W., Plaisted, R.L., Tanksley, S.D., 1988. RFLP Maps Based on a Common Set of Clones Reveal Modes of Chromosomal Evolution in Potato and Tomato. Genetics 120:1095-1103.

Bradshaw, J., 2007. Potato breeding strategy. pp. 157-177. In: Vreugdenhil, D., Bradshaw, J., Gebhardt, C., Govers, F., Taylor, M.A., MacKerron, D.K. and Ross, H.A. (Eds.), Potato Biology and Biotechnology, Elsevier Science B.V., Amsterdam.

Bradshaw, J.E. and Ramsay, G., 2005. Utilisation of the Commonwealth Potato Collection in potato breeding. Euphytica, 146(1-2): 9-19.

Brown, C., 2005. Antioxidants in potato. American Journal of Potato Research, 82:163-172.

Brown, C.R. 2011. The contribution of traditional potato breeding to scientific potato improvement. Potato Research, 54(4): 287-300.

Buck, R., Akeley, R., 1967. Effect of maturity, storage temperature, and storage time on greening of potato tubers. American Journal of Potato Research, 44: 56-58.

Burton, W.G., 1989. The Potato 3rd ed. Longman scientific and technical. England.

Buso, J.A., Boiteux, L.S. and Peloquin, S.J., 2000. Heterotic effects for yield and tuber solids and type of gene action for five traits in $4 x$ potato families derived from interploid (4x-2x) crosses. Plant breeding, 119(2): 111-117.

Buttery, R.G., Guadagni, D.G. and Ling, L.C., 1973. Volatile components of baked potatoes. Journal of the Science of Food and Agriculture, 24(9): 1125-1131.

Carputo, D., Aversano, R. and Frusciante, L., 2004. Breeding potato for quality traits. In Meeting of the Physiology Section of the European Association for Potato Research, 684: 55-64.

Celis Gamboa, C., P.C. Struik, E. Jacobsen and R.G.F. Visser., 2003, Ann. Appl. Biol. 143: 175.

CIP, 2021. Potato facts and figures. Available at https://cipotato.org/potato/ [accessed on May 25, 2021 ].

Coetzer, C., Corsini, D., Love, S., Pavek, J. and Tumer, N., 2001. Control of enzymatic browning in potato (Solanum tuberosum L.) by sense and antisense RNA from tomato polyphenol oxidase. Journal of Agricultural and Food Chemistry, 49(2), pp.652-657.

Coleman, E.C., Ho, C.T. and Chang, S.S., 1981. Isolation and identification of volatile compounds from baked potatoes. Journal of Agricultural and Food Chemistry, 29(1): 42-48.

Dale, M.F.B. and Mackay, G.R., 1994. Inheritance of table and processing quality. pp. 285-315. In: J.E. Bradshaw and G.R. Mackay (eds.), Potato Genetics. CAB International, Wallingford, Oxon, UK.

De Jong, H., Burns, V., 1993. Inheritance of tuber shape in cultivated diploid potatoes. American Journal of Potato Research, 70: 267-284.

Devaux A, Kromann P, Ortiz O., 2014. Potatoes for sustainable global food security. Potato Research, 57:185199.

Dodds, K., Long, D., 1955. The inheritance of colour in diploid potatoes. Journal of Genetics 53:136-149.

Elfnesh, F., Tekalign, T. and Solomon, W., 2011. Processing quality of improved potato (Solanumtuberosum L.) cultivars as influenced by growing environment and blanching. African Journal of Food Science, 5(6), 324332.

Ewing, E.E. and Struik, P.C., 1992. Tuber formation in potato: induction, initiation, and growth. Horticultural reviews, 14(89): 197.

Faivre-Rampant, O., Bryan, G.J., Roberts, A.G., Milbourne, D., Viola, R., Taylor, M.A., 2004. Regulated expression of a novel TCP domain transcription factor indicates an involvement in the control of meristem activation processes in Solanum tuberosum. Journal of Experimental Botany, 55: 951-953.

Friedman, M., 1997. Chemistry, biochemistry, and dietary role of potato polyphenols. A review. Journal of agricultural and food chemistry, 45(5): 1523-1540.

Friedman, M., 2006. Potato Glycoalkaloids and Metabolites: Roles in the Plant and in the Diet. Journal of Agricultural and Food Chemistry, 54:8655-8681.

Friedman, M., Levin C.E., 2009. Analysis and Biological Activities of Potato Glycoalkaloids, Calystegine 
Alkaloids, Phenolic Compounds, and Anthocyanins. pp. 127-161. In: S. Jaspreet and K. Lovedeep (Eds.), Advances in Potato Chemistry and Technology, Academic Press, San Diego.

Friedman, M., Mc Donald G.M., Filadelfi-Keszi M., 1997. Potato Glycoalkaloids: Chemistry, Analysis, Safety, and Plant Physiology. Critical Reviews in Plant Sciences, 16:55-132.

Gebremedhin, W., Endale, G., Lemaga, B., 2008. Potato Agronomy. In: Gebremedhin W, Endale G and Lemaga B (eds), Root and tuber crops: The untapped resources, Ethiopian Institute of Agricultural Research, Ethiopia, pp. 33-36

Griffiths, D.W. Dale, M.F.B. 2001. Effect of Light Exposure on the Glycoalkaloid Content of Solanum phureja Tubers. Journal of Agricultural and Food Chemistry, 49: 5223-5227.

Griffiths, D.W., Bain, H., Dale, M.F.B. 1998. Effect of Storage Temperature on Potato (Solanum tuberosum L.) Tuber Glycoalkaloid Content and the Subsequent Accumulation of Glycoalkaloids and Chlorophyll in Response to Light Exposure. Journal of Agricultural and Food Chemistry, 46: 5262-5268.

Gumul, D., Ziobro, R., Noga, M., Sabat, R., 2011. Characterisation of five potato cultivars according to their nutritional and pro-health components. Acta scientiarum Polonorum Technologia Alimentaria, 10(1): 73-81.

Haase, N.U., 2004. Estimation of dry matter and starch concentration in potatoes by determination of underwater weight and near infrared spectroscopy. Potato Res. 46:117-127.

Haverkort, A.J., 2007. Potato crop response to radiation and day length pp. 353-365. In: Vreugdenhil, D., Bradshaw, J., Gebhardt, C., Govers, F., Taylor, M.A., MacKerron, D.K. and Ross, H.A. (Eds.), Potato biology and biotechnology: advances and perspectives. Elsevier, London.

Hughes, J.C. 1974. Factors influencing the quality of ware potatoes. 2. Environmental factors. Potato Research, 17(4): 512-547.

Hung, C.-Y., Murray, J.R., Ohmann, S.M., Tong, C.B.S., 1997. Anthocyanin Accumulation during Potato Tuber Development. J. Amer. Soc. Hort. Sci. 122:20-23.

Jansen, G., Flamme, W., 2006. Coloured potatoes (Solanum tuberosum L.) Anthocyanin Content and Tuber Quality. Genetic Resources and Crop Evolution 53:1321-1331.

Jansky, S., 2009. Breeding, genetics and cultivar development. pp. 27-62. In: J. Singh and L. Kaur (Eds.), Advances in potato chemistry and technology. Academic Press, Burlington, VT.

Jansky, S.H., 2010. Potato flavor. American Journal of Potato Research, 87(2), pp.209-217.

Killick, R.J. and Simmonds, N.W., 1974. Specific gravity of potato tubers as a character showing small genotype-environment interactions. Heredity, 32(1): 109-112.

Kirkman, M., 2007. Global markets for processed potato products, in: D. Vreugdenhil, et al. (Eds.), Potato Biology and Biotechnology, Elsevier Science B.V., Amsterdam. pp. 27-44.

Korpan, Y.I., Nazarenko, E.A., Skryshevskaya, I.V., Martelet, C., Jaffrezic-Renault, N. and Anna, V., 2004. Potato glycoalkaloids: true safety or false sense of security?. Trends in biotechnology, 22(3): 147-151.

Kozukue, N., Yoon, K.S., Byun, G.I., Misoo, S., Levin, C.E. and Friedman, M., 2008. Distribution of glycoalkaloids in potato tubers of 59 accessions of two wild and five cultivated Solanum species. Journal of agricultural and food chemistry, 56(24), pp.11920-11928.

Laboski, C., Kelling, K., 2007. Influence of fertilizer management and soil fertility on tuber specific gravity: a review. American Journal of Potato Research, 84: 283-290.

Lachman, J., Hamouz, K., Sulc M., Orsák, M., Pivec, V., Hejtmánková, A., Dvorák, P., Cepl, J., 2009.Cultivar differences of total anthocyanins and anthocyanidins in red and Purple - fleshed potatoes and their relation to antioxidant activity. Food Chemistry, 114:836-843.

Lebecka, R. and Zimnoch-Guzowska, E., 2004. The inheritance of resistance to soft rot (Erwinia carotovora subsp. atroseptica) in diploid potato families. American journal of potato research, 81(6), pp.395-401.

Lewis, C.E., Walker, J.R.L., Lancaster, J.E., Sutton, K.H., 1998. Determination of anthocyanins, flavonoids and phenolic acids in potatoes. I: Coloured cultivars of Solanum tuberosum L. Journal of the Science of Food and Agriculture, 77: 45-57.

Lewis, W., Rowberry, R., 1973. Some effects of planting depth and time and height of hilling on Kennebec and Sebago potatoes. American Journal of Potato Research, 50: 301-310.

Li X.Q., De Jong, H., De Jong, D.M., De Jong, W.S., 2005. Inheritance and genetic mapping of tuber eye depth in cultivated diploid potatoes. TAG Theoretical and Applied Genetics 110:1068-1073.

Love, S. L., Pavek, J. J., Thompson-Johns, A. and Bohl, W., 1998. Breeding progress for potato chip quality in North America cultivars. Am. J. Potato Res., 75: 27-36.

Mackay, G., 2007. Propagation by traditional breeding methods. Vol. 1. Potato. Pp. 65-81. In: Razdan MK \& A Mattoo (eds). Genetic improvement of Solanaceous crops. Enfield Science Publishers, NH.

Maga, J.A. and Holm, D.G., 1992. Subjective and objective comparison of baked potato aroma as influenced by varieties/clone. pp. 537-541. In: G. Charalambous (Ed.), Food Science and Nutrition. Elsevier Science Publishers, Amsterdam.

Maga, J.A. and Sizer, C.E., 1973. Pyrazines in foods. Review. Journal of Agricultural and Food Chemistry, 
21(1), pp.22-30.

Maga, J.A., 1994. Potato flavor. Food Reviews International, 10(1), pp.1-48.

Menendez, C., Ritter, E., Schafer-Pregl, R., Walkemeier, B., Kalde, A., Salamini, F., Gebhardt, C., 2002. Cold Sweetening in Diploid Potato: Mapping Quantitative Trait Loci and Candidate Genes. Genetics, 162: 14231434.

Meyer, R.C., Milbourne, D., Hackett, C.A., Bradshaw, J.E., McNichol, J.W. and Waugh, R., 1998. Linkage analysis in tetraploid potato and association of markers with quantitative resistance to late blight (Phytophthora infestans). Molecular and General Genetics MGG, 259(2): 150-160.

Monteros, A., 2011. Potato landraces: description and dynamics in three areas of Ecuador, Plant breeding, Wageningen University, Wageningen, The Netherlands. pp.160.

Nayak, B., Berrios, J.D.J., Powers, J.R., Tang, J., Ji Y., 2011. Colored Potatoes (Solanum Tuberosum L.) dried for antioxidant-rich value added foods. Journal of Food Processing and Preservation, 35: 571-580.

Ovchinnikova, A., Krylova, E., Gavrilenko, T., Smekalova, T., Zhuk, M., Knapp, S. and Spooner, D.M., 2011. Taxonomy of cultivated potatoes (Solanum section Petota: Solanaceae). Botanical Journal of the Linnean Society, 165(2): 107-155.

Parfitt, D. and Peloquin, S., 1981. The genetic basis for tuber greening in 24-chromosome potatoes. American Journal of Potato Research, 58: 299-304.

Pavek, J.J. and Corsini, D.L., 2001. Utilization of potato genetic resources in variety development. American Journal of Potato Research, 78(6), pp.433- 441

Percival, G.C., 1999. The influence of light upon glycoalkaloid and chlorophyll accumulation in potato tubers (Solanum tuberosum L.). Plant Science, 145: 99-107.

Reeves, A., 1988. Varietal differences in potato tuber greening. American Journal of Potato Research, 65:651658.

Reyes, L., Miller, J., Cisneros-Zevallos, L., 2004. Environmental conditions influence the content and yield of anthocyanins and total phenolics in purple- and red-flesh potatoes during tuber development. American Journal of Potato Research, 81: 187-193.

Simmonds, N.W., 1979. Principles of crop improvement. Longman, London.

Sinden, S., Webb R., 1972. Effect of variety and location on the glycoalkaloid content of potatoes. American Journal of Potato Research, 49:334-338.

Śliwka, J., Jakuczun, H., Chmielarz, M., Hara-Skrzypiec, A., Tomczyńska, I., Kilian, A. and ZimnochGuzowska, E., 2012. A resistance gene against potato late blight originating from Solanum $\times$ michoacanum maps to potato chromosome VII. Theoretical and Applied Genetics, 124(2): 397-406.

Sowokinos, J.R., 2007. The canon of potato science: 38. Carbohydrate metabolism. Potato Research, 50(3), pp.367-370.

Spooner, D.M. Núñez, J., Trujillo, G., del Rosario Herrera, M., Guzmán, F. and Ghislain, M., 2007. Extensive simple sequence repeat genotyping of potato landraces supports a major reevaluation of their gene pool structure and classification. Proceedings of the National Academy of Sciences of the United States of America, 104(49): 19398-19403.

Storey, M., 2007. The Harvested Crop. pp. 441-470. In: Vreugdenhil, D., Bradshaw, J., Gebhardt, C., Govers, F., Taylor, M.A., MacKerron, D.K. and Ross, H.A. (Eds.), Potato biology and biotechnology: advances and perspectives. Elsevier, Amsterdam.

Suttle, J., 2004. Physiological regulation of potato tuber dormancy. American Journal of Potato Research, 81: 253-262.

Tarn, T. R., Tai, G. C. C. and Liu, Q., 2006. Quality improvement. Pp 147-178. In: J. Gopal and S. M. P. Khurana. (eds.), Handbookof potato production, improvement, and postharvest management. The Haworth Press, Inc., New York, NY.

Taylor, M.A., McDougall, G.J. and Stewart, D., 2007. Potato flavour and texture. pp. 525-540. In: Vreugdenhil, D., Bradshaw, J., Gebhardt, C., Govers, F., Taylor, M.A., MacKerron, D.K. and Ross, H.A. (Eds.), Potato biology and biotechnology: advances and perspectives. Elsevier Science B.V., Amsterdam.

Teow, C.C., Truong, V.-D., McFeeters, R.F., Thompson, R.L., Pecota, K.V., Yencho, G.C., 2007. Antioxidant activities, phenolic and [beta]-carotene contents of sweet potato genotypes with varying flesh colours. Food Chemistry, 103:829-838.

Tesfaye Abebe, Wongchaochant, S. and Taychasinpitak, T., 2013. Evaluation of specific gravity of potato varieties in Ethiopia as a criterion for determining processing quality. Kasetsart Journal of Natural Science, 47. 30-41.

Turakainen, 2007. Selenium and Its Effects on Growth, Yield and Tuber Quality in Potato; HELSINKI 2007

Van den Berg, J., Ewing, E., Plaisted, R., McMurry, S., Bonierbale, M., 1996. QTL analysis of potato tuber dormancy. TAG Theoretical and Applied Genetics, 93: 317-324.

Van Eck, H., 2007. Genetics of morphological and tuber traits. pp. 91-115. .In: Vreugdenhil, D., Bradshaw, J., 
Gebhardt, C., Govers, F., Taylor, M.A., MacKerron, D.K. and Ross, H.A. (Eds.), Potato biology and biotechnology: advances and perspectives. Elsevier, London.

Van Eck, H.J., Jacobs, J.M.E., Van den Berg, P.M.M.M., Stiekema, W.J., Jacobsen, E. 1994. The inheritance of anthocyanin pigmentation in potato (Solanum tuberosum L.) and mapping of tuber skin colour loci using RFLPs. Heredity 73:410-421.

Viola, R., 2000. Tuber filling and starch synthesis in potato. In Carbohydrate Reserves in Plants.

Wassu, M., 2016. Specific Gravity, Dry Matter Content, and Starch Content of Potato (Solanumtuberosum L.) Varieties Cultivated in Eastern Ethiopia. East African Journal of Science, 10(2): 87-102.

Werij, J.S., 2011. Genetic analysis of potato tuber quality traits. Doctoral dissertation, Wageningen University.

Werij, J.S., Furrer, H., Van Eck, H.J., Visser, R.G. and Bachem, C.W., 2012. A limited set of starch related genes explain several interrelated traits in potato. Euphytica, 186(2): 501-516.

Werij, J.S., Kloosterman, B., Celis-Gamboa, C., De Vos, C.R., America, T., Visser, R.G. and Bachem, C.W., 2007. Unravelling enzymatic discoloration in potato through a combined approach of candidate genes, QTL, and expression analysis. Theoretical and Applied Genetics, 115(2): 245-252.

Wiltshire, J.J. and Cobb, A.H., 1996. A review of the physiology of potato tuber dormancy.Annals of Applied Biology, 129: 553-569. 